\title{
Soropositividade para Leptospira sp. e sorogrupos predominantes em cães do Pantanal Brasileiro*
}

\section{Seropositivity for Leptospira sp. and predominant serogroups in dogs from the Brazilian Pantanal}

\author{
Maria Lúcia Spanga, ${ }^{* *}$ Diego Figueiredo da Costa, ${ }^{* * *}$ Sérgio Santos de Azevedo, ${ }^{* * *}$ Andréia Lima Tomé Melo, ${ }^{* *}$ \\ Daniel Moura de Aguiar, ${ }^{* * *}$ Lázaro Manoel de Camargo**
}

\section{Resumo}

Em face à grande importância que a leptospirose possui no contexto sanitário mundial, tanto no aspecto humano como animal, este estudo teve por objetivo realizar a pesquisa de anticorpos anti-Leptospira sp. pela técnica de Soroaglutinação Microscópica (SAM) em 429 amostras de soros de cães provenientes de quatro municípios (Poconé/MT, Santo Antônio de Leverger/MT, Barão de Melgaço/MT e Corumbá/MS) localizados na região do Pantanal Brasileiro, bem como foram verificadas possíveis associações entre os resultados dos exames sorológicos e respostas aos questionários epidemiológicos aplicados aos proprietários. Do total de cães avaliados pela SAM (título $\geq 100)$, verificou-se que 34 (7,93\%; IC 95\%: 5,63\%-11,00\%) cães tinham anticorpos antiLeptospira sp. Os títulos encontrados variaram entre 100 e 1600 e todos os municípios analisados tinham cães sororreagentes ao agente pesquisado. O sorogrupo reator mais frequente foi o Icterohaemorrhagiae, seguido pelo Australis. Por outro lado, foram observadas menores proporções de cães reagentes aos sorogrupos Tarassovi, Hebdomadis, Autumnalis e Grippotyphosa. As variáveis associadas com a ocorrência de leptospirose foram habitat rural $(P<0,01)$ e área alagável $(P=0,01)$. Estes resultados demonstram que os cães da região pantaneira tiveram contato com agentes do gênero Leptospira, o que representa uma informação relevante para a saúde pública local devido à importância zoonótica da doença.

Palavras-chave: Anticorpos, Leptospirose, Soroaglutinação Microscópica, Brasil.

\begin{abstract}
Given the great importance that leptospirosis has the global health context, both in human and animal aspect, this study aimed to search for antibodies anti-Leptospira sp. by the technique of microscopic agglutination test (MAT) in 429 samples of sera from dogs from four municipalities (Poconé/MT, Santo Antônio de Leverger/MT, Barão de Melgaço/MT and Corumbá/MS) located in the Brazilian Pantanal region, in order for determine associations between the results of the serological tests and answers to epidemiological questionnaires applied to owners. Of the total dogs evaluated by MAT (titer $\geq 100)$, it was verified that $34(7.93 \%, 95 \% \mathrm{Cl}: 5.63 \%$ $-11.00 \%$ ) dogs had antibodies against Leptospira sp. The titers found ranged from 100 to 1600 and all municipalities analyzed had seroreactive dogs for the investigated agent. The most frequent serogroup reactor was Icterohaemorrhagiae, followed by Australis. On the other hand, smaller proportions of reactive dogs were observed for serogroups Tarassovi, Hebdomadis, Autumnalis and Grippotyphosa. The variables associated with the occurrence of leptospirosis were rural habitat $(P<0.01)$ and flooded area $(P=0.01)$. These results demonstrate that dogs from the Pantanal region had contact with agents of the genus Leptospira, which represents information relevant to local public health due to the zoonotic importance of the disease.
\end{abstract}

Keywords: Antibodies, leptospirosis, Microscopic Soroagglutination, Brazil.

\section{Introdução}

A leptospirose é uma importante doença zoonótica de ocorrência mundial que acomete tanto animais domésticos quanto silvestres, e tem como agente etiológico bactérias do gênero Leptospira (Ellis, 2015). Trata-se de uma enfermidade de grande relevância, sendo responsável por perdas econômicas na agropecuária e com grande repercussão na saúde pública (Adler, 2015; Costa et al., 2015).

A ocorrência da doença está associada com fatores climáticos, manejo e presença de hospedeiros do agente (Adler, 2015). $\mathrm{Na}$ presença de hospedeiros e, em condições ambientais favoráveis, as bactérias podem permanecer por semanas ou meses em regiões tropicais e subtropicais (Martins e Lilenbaum,

\footnotetext{
*Recebido em 22 de abril de 2019 e aceito em 12 de agosto de 2019.

**Programa de Pós-Graduação Stricto Sensu em Biociência Animal; Universidade de Cuiabá (UNIC); Cuiabá; Mato Grosso; Brasil.

***Unidade Acadêmica de Medicina Veterinária (UAMV); Centro de Saúde e Tecnologia Rural (CSTR); Universidade Federal de Campina Grande (UFCG);

Patos; Paraíba; Brasil.

${ }^{* * * *}$ Faculdade de Medicina Veterinária; Universidade Federal de Mato Grosso (UFMT); Cuiabá; Mato Grosso; Brasil.

Autora para correspondência: andreialtm@gmail.com
} 
2014). Apesar de os ratos (Rattus norvegicus) atuarem como reservatórios do patógeno e serem a principal fonte de infecção para o ser humano, sabe-se que os cães também desempenham este papel (Silva et al., 2018). Assim, a relação estreita entre cães e seres humanos ao longo da história faz com que esses animais tenham um desempenho importante na epidemiologia da doença (Rojas et al., 2010). Miotto et al. (2018), após isolarem leptospiras de urina de cães assintomáticos, sugerem a participação dos animais dessa espécie como reservatórios, potencializando a atuação dessa espécie como fonte de infecção do agente.

Nesse sentido, o Pantanal, que é um bioma caracterizado por ser a maior planície alagável do planeta, alberga grande diversidade de fauna e propicia condições ecológicas favoráveis ao desenvolvimento de leptospiras em função da possibilidade da bactéria sobreviver por mais tempo em áreas alagadas e com elevadas temperaturas (Adler, 2015). Apesar da relevância dos cães na epidemiologia da leptospirose, estudos nesses animais na região pantaneira ainda são escassos. Ademais, investigações nesse âmbito são necessárias devido à forte influência que o ambiente pantaneiro pode exercer sobre a disseminação desta bactéria, o que poderia comprometer também a saúde pública regional em função do caráter zoonótico desta doença. Dessa maneira, o objetivo deste estudo foi determinar a soropositividade para Leptospira sp. e os sorogrupos predominantes em cães da região do Pantanal brasileiro.

\section{Material e métodos}

Para execução deste trabalho foram avaliadas 429 (160 provenientes de área urbana e 269 de área rural) amostras de soros de cães colhidas no período de 2009 a 2012, de quatro municípios localizados na região do Pantanal: i) Poconé $\left(16^{\circ}\right.$ 15' 24" S; 56 37' 22" O); ii) Santo Antônio de Leverger (15 51 ' 47" S; 56 04' 47" O); iii) Barão de Melgaço (16 11' 49" S; $55^{\circ}$ 58' 03" O) e iv) Corumbá (1900' 33"S; 57 39' 44" O). Estas amostras foram coletadas em estudos anteriores que avaliaram a presença de anticorpos contra riquetsias e leishmanias (Melo et al., 2011; Melo et al. 2017).

As amostras de sangue foram colhidas por venopunção da jugular para obtenção do soro, e um questionário epidemiológico foi aplicado a cada proprietário. As informações coletadas incluíram habitat (urbano ou rural), área (não alagável e alagável), sexo e idade do animal.

Para a pesquisa de anticorpos anti-Leptospira sp. foi utilizada a técnica de Soroaglutinação Microscópica (SAM) (OIE, 2014), utilizando como antígenos uma coleção de estirpes de Leptospira biflexa sorovares Andamana e Patoc, Leptospira interrogans sorovares Australis, Copenhageni, Bataviae, Bratislava, Canicola, Grippotyphosa, Hardjoprajitno, Pomona, Pyrogenes, Icterohaemorrhagiae, Hebdomadis, Wolffi e Butembo; Leptospira borgpetersenii sorovares Autumnalis, Castellonis, Hardjobovis Javanica e Tarassovi; Leptospira santarosai sorovares Guaricura e Shermani; Leptospira kirschneri sorovar Cynopteri; e Leptospira noguchii sorovar Panama Os soros foram triados na diluição de 1:100, e aqueles que apresentaram $50 \%$ ou mais de aglutinação foram titulados pelo exame de uma série de diluições geométricas de razão dois. O título do soro foi a recíproca da maior diluição que apresentou resultado positivo. Os antígenos foram examinados ao microscópio de campo escuro, previamente aos testes, a fim de verificar a mobilidade e a presença de auto-aglutinação ou de contaminantes (OIE, 2014).

O estudo de associação entre os resultados dos exames sorológicos e as variáveis obtidas com o questionário epidemiológico foi realizado com o teste do qui-quadrado $\left(\mathrm{c}^{2}\right)$ ou o teste exato de Fisher, quando necessário, utilizando o programa Epilnfo 7.1 (Epilnfo $^{\text {TM }} 7$, 2019).

Este estudo foi aprovado pelo Comitê de Ética de Uso de Animais da Universidade Federal de Mato Grosso (UFMT), sob número de protocolo 23108.019742/09-9.

\section{Resultados e discussão}

O presente estudo demonstrou a presença de anticorpos antiLeptospira sp. em 34 de 429 (7,93\%; IC 95\%: 5,63\%-11,00\%) cães de quatro municípios que pertencem ao bioma pantaneiro. Trata-se de um levantamento sorológico relevante para a área de estudo já que pesquisas sobre este agente na população canina do Pantanal ainda são escassas. Ressalta-se a importância do conhecimento dos sorogrupos circulantes numa região, pois isso possibilita o melhor conhecimento da epidemiologia da doença nesse local (Pinto et al., 2015). Inúmeros trabalhos avaliaram a ocorrência de animais sororreagentes a diversos sorovares de Leptospira sp. em outras regiões do Brasil, cujos resultados são variáveis, denotando que determinadas características epidemiológicas podem interferir numa maior ou menor circulação do agente (Aguiar et al., 2007; Azevedo et al., 2011; Jorge et al., 2011; Santos et al., 2017).

Foram detectados títulos anti-Leptospira sp. de $100(n=2)$, $200(n=11), 400(n=17), 800(n=2)$ e $1600(n=2)$. Cães de área urbana foram somente dois e apresentaram títulos de 200 e 400; os demais eram todos de ambiente rural, sendo que todos os municípios analisados apresentaram cães sororreativos (Tabela 1), (Figura 1).

O sorogrupo mais frequente foi o Icterohaemorrhagiae (sorovares Icterohaemorrhagiae e Copenhageni) com 19 cães reagentes, dos quais 10 apresentaram reações para Icterohaemorrhagiae (dois cães urbanos e oito rurais) enquanto nove cães do meio rural reagiram para Copenhageni. Ambos os sorovares são mantidos por roedores sinantrópicos e apresentam elevada prevalência em cães e seres humanos em algumas regiões do país (Rodrigues et al., 2013; Mesquita et al., 2017). A presença desse sorogrupo possivelmente tem relação com condições sanitárias e ambientais que facilitam o contato dos caninos com o seu hospedeiro natural, o rato de esgoto (Rattus novergicus) (Adler, 2015).

O sorogrupo Australis (sorovar Bratislava) foi o segundo mais frequente, com sete $(1,63 \%)$ cães positivos e todos de ambiente rural. Anticorpos contra Bratislava já foram relatados em diversas espécies, como pequenos e grandes ruminantes (Aguiar et al., 2006; Costa et al., 2016) e equinos (Hashimoto et al., 2007) de diferentes locais do Brasil. Considerando a provável adaptação do sorovar Brastislava aos equinos (Hamond et al., 2014), aliada à histórica e importante presença de equídeos na região (Santos et al., 1992), era de se esperar que uma proporção de cães fosse reagir frente a esse sorovar, uma vez que se observa estreito contato entre essas espécies nas fazendas da região (informação pessoal - dados não publicados). 
Tabela 1: Distribuição dos sorogrupos de Leptospira sp. e respectivos títulos de anticorpos em cães dos municípios analisados no período de 2009 a 2012

\begin{tabular}{|c|c|c|c|c|c|c|c|c|}
\hline \multirow[b]{2}{*}{ Sorogrupos } & \multicolumn{2}{|c|}{ Poconé } & \multicolumn{2}{|c|}{ Santo Antônio de Leverger } & \multicolumn{2}{|c|}{ Barão de Melgaço } & \multicolumn{2}{|c|}{ Corumbá } \\
\hline & $\begin{array}{c}\text { Positivos/ } \\
\text { testados } \\
(\%)\end{array}$ & $\begin{array}{l}\text { Títulos detectados } \\
\left.\text { ( } n^{\circ} \text { de cães }\right)\end{array}$ & $\begin{array}{c}\text { Positivos/ } \\
\text { testados } \\
(\%)\end{array}$ & $\begin{array}{c}\text { Títulos } \\
\text { detectados } \\
\text { (no de cães) }\end{array}$ & $\begin{array}{c}\text { Positivos/ } \\
\text { testados } \\
(\%)\end{array}$ & $\begin{array}{c}\text { Títulos } \\
\text { detectados } \\
\text { (nº de cães) }\end{array}$ & $\begin{array}{c}\text { Positivos/ } \\
\text { testados } \\
(\%)\end{array}$ & $\begin{array}{c}\text { Títulos } \\
\text { detectados } \\
\text { ( } \mathrm{n}^{\circ} \text { de cães) }\end{array}$ \\
\hline Icterohaemorrhagiae & $8 / 319(2,50)$ & $\begin{array}{c}100(7) 200(6) \\
400(4)\end{array}$ & $2 / 16(12,5)$ & $\begin{array}{l}200(6) \\
400(2)\end{array}$ & $7 / 45(15,55)$ & $\begin{array}{l}100(4) 200(11) \\
400(8) 1600(2)\end{array}$ & $2 / 49(4,08)$ & $\begin{array}{l}200(3) \\
400(3) \\
800(1)\end{array}$ \\
\hline Grippotyphosa & $1 / 319(0,31)$ & 200 (1) 400 (1) & $0 / 16(0)$ & - & $0 / 45(0)$ & - & $0 / 49(0)$ & - \\
\hline Tarassovi & $2 / 319(0,62)$ & 100 (1) 200 (1) & $0 / 16(0)$ & - & $0 / 45(0)$ & - & $0 / 49(0)$ & - \\
\hline Australis & $4 / 319(1,25)$ & $\begin{array}{l}100(1) 200(7) \\
400(2) 800(1)\end{array}$ & $0 / 16(0)$ & - & $1 / 45(2,22)$ & $\begin{array}{l}100(1) \\
400(1)\end{array}$ & $2 / 49(4,08)$ & $\begin{array}{l}100(2) \\
200(2)\end{array}$ \\
\hline Hebdomadis & $2 / 319(0,62)$ & 100 (1) $200(1)$ & $0 / 16(0)$ & - & $0 / 45(0)$ & - & $0 / 49(0)$ & - \\
\hline Autumnalis & $1 / 319(0,31)$ & $200(1)$ & $0 / 16(0)$ & - & $0 / 45(0)$ & - & $1 / 49(2,04)$ & $400(1)$ \\
\hline Indeterminado & $0 / 319(0)$ & - & $0 / 16(0)$ & - & $0 / 45(0)$ & - & $1 / 49(2,04)$ & $\begin{array}{l}100(1) \\
200(5) \\
400(2)\end{array}$ \\
\hline
\end{tabular}

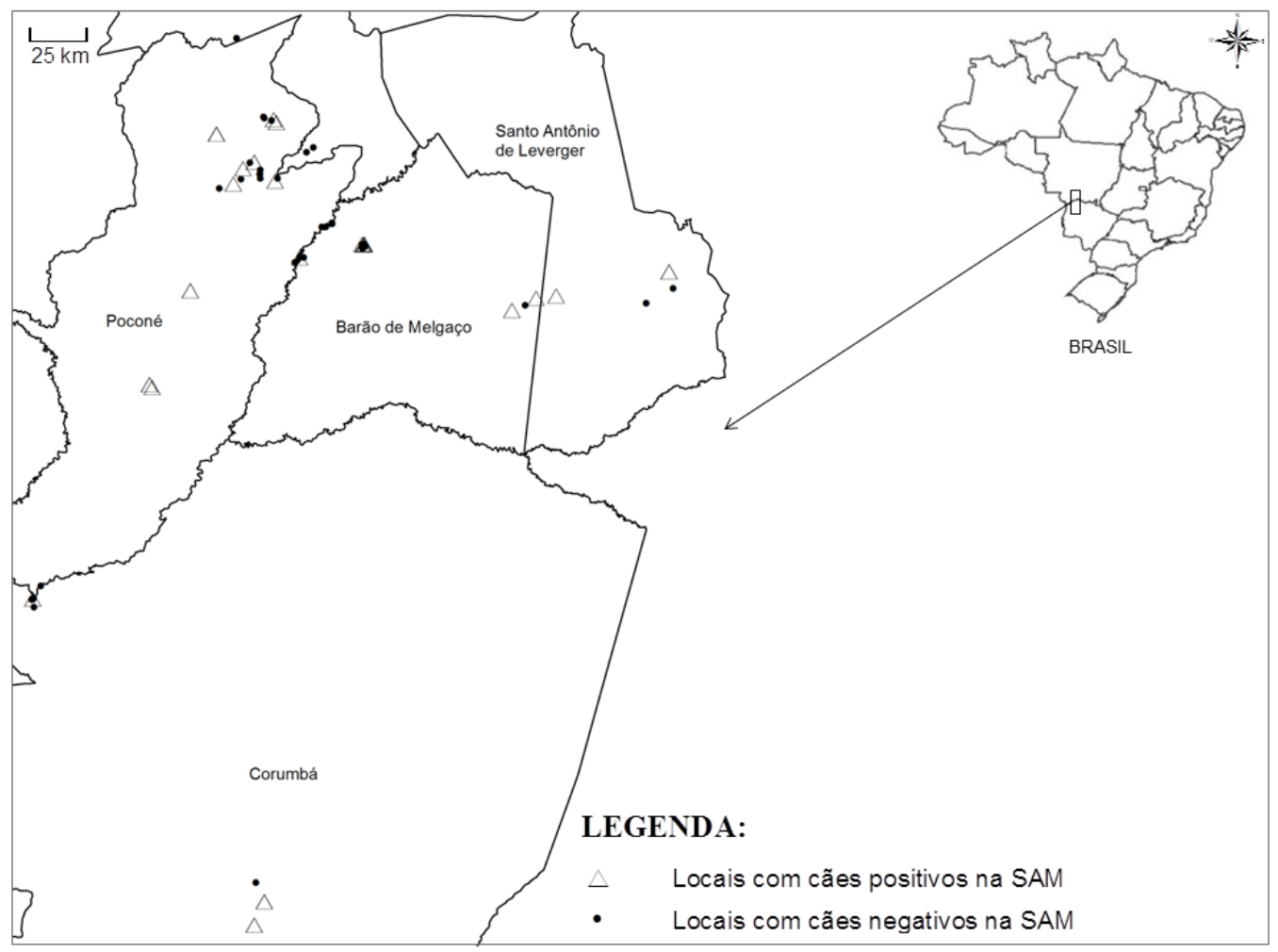

Figura 1: Distribuição dos cães amostrados entre os quatro munícipios do Pantanal Brasileiro no período de 2009 a 2012

Foram observadas menores proporções de cães reagentes aos sorogrupos Tarassovi (sorovar Tarassovi), Hebdomadis (sorovar Hebdomadis), Autumnalis (sorovar Autumnalis) e Grippotyphosa. Os resultados mostraram apenas um cão positivo $(0,23 \%)$ para o sorovar Grippotyphosa, ao passo que para os demais sorogrupos havia dois $(0,46 \%)$ cães reagentes.
São baixas as frequências para os sorovares supracitados, e sua ocorrência é sugestiva da presença de animais silvestres no local (Hartskeerl e Terpstra, 1996; Silva et al., 2015).

$\mathrm{Na}$ Tabela 2 são apresentados os resultados da análise de associação das variáveis epidemiológicas e a condição sorológica dos animais. 
Tabela 2: Estudo de associação entre os anticorpos antiLeptospira sp. e as variáveis analisadas nos cães da região do Pantanal entre 2009 a 2012

\begin{tabular}{|c|c|c|c|}
\hline \multirow{3}{*}{$\begin{array}{l}\text { Variáveis } \\
\text { analisadas }\end{array}$} & \multicolumn{3}{|c|}{$\mathrm{N}^{\circ}$ de cães } \\
\hline & \multirow{2}{*}{ Analisados } & \multicolumn{2}{|c|}{ Positivos para Leptospira sp. } \\
\hline & & Número (\%) & $P$-valor \\
\hline \multicolumn{4}{|l|}{ Habitat } \\
\hline Urbano & 160 & $2(1,25)$ & $<0,01$ \\
\hline Rural & 269 & $32(11,90)$ & \\
\hline \multicolumn{4}{|l|}{ Área } \\
\hline Área não alagável & 256 & $13(5,08)$ & 0,01 \\
\hline Área alagável & 173 & $21(12,14)$ & \\
\hline \multicolumn{4}{|l|}{ Sexo } \\
\hline Macho & 258 & $25(9,69)$ & 0,13 \\
\hline Fêmea & 171 & $9(5,26)$ & \\
\hline \multicolumn{4}{|l|}{ Idade* } \\
\hline $0-12$ meses & 124 & $8(6,45)$ & 0,25 \\
\hline $12-24$ meses & 100 & $5(5,0)$ & \\
\hline 24-48 meses & 94 & $8(8,51)$ & \\
\hline$>48$ meses & 98 & $12(12,2)$ & \\
\hline
\end{tabular}

*13 cães não tiveram a idade determinada pelos seus proprietários. Destes, apenas 1 tinha anticorpos anti-Leptospira sp. (título de 400 contra o sorovar Icterohaemorrhagiae).
As variáveis habitat rural e área alagável foram associadas à ocorrência de anticorpos anti-Leptospira sp. nos cães. A associação entre áreas rurais e alagáveis justifica-se pela presença de hospedeiros mantenedores e pelas condições ambientais propícias para a manutenção e transmissão de leptospiras, já que o agente sobrevive mais tempo em áreas alagadas e de temperaturas elevadas (Ellis, 2015) e, nesse sentido, o Pantanal, que pertence à bacia do rio Paraguai é considerado a maior extensão úmida do planeta, sendo considerado uma imensa planície de áreas alagáveis. Além disso, a grande diversidade de mamíferos que dividem o mesmo habitat pode contribuir para a manutenção de agentes infecciosos, incluindo o gênero Leptospira (Vieira et al., 2013; Adler, 2015; Silva et al., 2015). Ademais, deve ser considerado o baixo número de cães de área urbana soropositivos, o que reforça o provável contato destes animais com animais portadores de ambiente rural.

\section{Conclusões}

A partir dos resultados observados no presente estudo é possível depreender que os cães da região pantaneira, especialmente os de ambiente rural e os que habitam área alagável, tiveram contato com agentes do gênero Leptospira, o que representa uma informação relevante para a saúde pública local, principalmente devido à implicação zoonótica da doença.

\section{Agradecimentos}

Os autores agradecem ao J.T. de Melo e E.C.L.T. de Melo, Cuiabá, MT, Brasil, pelo apoio técnico; a Estação Ecológica SESC Pantanal, ao Parque Nacional do Pantanal Matogrossense e Instituto Chico Mendes de Conservação da Biodiversidade - ICMBio pelo apoio logístico. A Coordenação de Aperfeiçoamento de Pessoal de Nível Superior (CAPES) pela bolsa de A.L.T. Melo e ao Conselho Nacional de Desenvolvimento Científico e Tecnológico (CNPq) pela bolsa de produtividade científica à D.M. Aguiar.

\section{Referências}

ADLER, B. History of leptospirosis and Leptospira. Current Topics in Microbiology and Immunology, v.387, p.79-84, 2015.

AGUIAR, D.M.; GENNARI, S.M.; CAVALCANTE, G.T.; LABRUNA, M.B.; VASCONCELLOS, S.A.; RODRIGUES, A.A.R.; MORAES, Z.M.; CAMARGO, L.M.A. Seroprevalence of Leptospira spp. in cattle from Monte Negro Municipality, Western Amazon, Brazil. Pesquisa Veterinária Brasileira, v.26, n.2, p.102-104, 2006.

AGUIAR, D.M.; CAVALCANTE, G.T.; MARVULO, M.F.V.; SILVA, J.C.R.; PINTER, A.; VASCONCELLOS, S.A.; MORAIS, Z.M.; LABRUNA, M.B.; CAMARGO, L.M.A.; GENNARI, S.M. Fatores de risco associados à ocorrência de anticorpos anti-Leptospira spp. em cães do município de Monte Negro, Rondônia, Amazônia Ocidental Brasileira. Arquivo Brasileiro de Medicina Veterinária e Zootecnia, v.59, n.1, p.70-76, 2007.

AZEVEDO, S.S.; FERNANDES, A.R.F.; QUEIROGA, I.M.B.N.; ALVES, C.J.; MORAIS, Z.M.; SANTOS, C.S.A.B.; VASCONCELLOS, S.A. Ocorrência e fatores de risco associados à leptospirose em cães atendidos em hospital veterinário no semiárido paraibano. Brazilian Journal of Veterinary Research and Animal Science, v.48, n.2, p.161-166, 2011.
COSTA, F.; HAGAN. J.E.; CALCAGNO, J.; KANE, M.; TORGERSON, P.; MARTINEZ-SILVEIRA, M.S.; STEIN, C.; ABELA-RIDDER, B.; KO, A.I. Global morbidity and mortality of leptospirosis: a systematic review. PLOS Neglected Tropical Diseases, v.17, n.9, p.1-19, 2015.

COSTA, D.F.; SILVA, A.F.; FARIAS, A.E.M.; BRASIL, A.W.L.; SANTOS, F.A.; GUILHERME, R.F.; AZEVEDO, S.S.; ALVES, C.J. Serological study of the Leptospira spp. infection in sheep and goats slaughtered in the State of Paraíba, semiarid of Northeastern Brazil. Semina: Ciências Agrárias, v.37, n.2, p.819828, 2016.

ELLIS, W.A. Animal Leptospirosis. Current Topics in Microbiology and Imunology, v.387, n.1, p.99-137, 2015.

Epilnfo $^{\mathrm{TM}}$ 7. Version 7.1.4. Atlanta: Centers for Disease Control and Prevention, 2019. Disponível em: <http://www.cdc.gov/ epiinfo>. Acesso em: 01 fev. 2019.

HAMOND, C.; MARTINS, G.; BREMONT, S.; MEDEIROS, M.; BOURHY, P.; LILENBAUM, W. Predominance of Leptospira spp. interrogans serovar Bratislava DNA in vaginal fluid of mares suggests sexual transmission of leptospirosis. Animal Reproduction Science, v.151, n.3-4, p.275-279, 2014.

HARTSKEERL, P.A.; TERPSTRA, W.J. Leptospirosis in wild animals. Veterinary Quarterly, v.18, supl.3, p.149-150, 1996. 
HASHIMOTO, V.Y.; GONÇALVES, D.D.; SILVA, F.G.; OLIVEIRA, R.C.; ALVES, L.A.; REICHMANN, P.; MULLER, E.E.; FREITAS, J.C. Occurrence of antibodies against Leptospira spp. in horses of the urban area of Londrina, Paraná, Brazil. Revista do Instituto de Medicina Tropical de São Paulo, v.49, n.5, p.327-330, 2007.

JORGE, R.S.; FERREIRA, F.; NETO, J.S.F.; VASCONCELLOS, S.A.; LIMA, E.S.; MORAIS, Z.M.; SOUZA, G.O. Exposure of freeranging wild carnivores, horses and domestic dogs to Leptospira spp. in the northern Pantanal, Brazil. Memórias do Instituto Oswaldo Cruz, v.106, n.4, p.441-444, 2011.

MARTINS, G.; LILENBAUM, W. Leptospirosis in sheep and goats under tropical conditions. Tropical Animal Health and Production, v.46, n, 1, p.11-17, 2014.

MELO, A.L.T.; MARTINS, T.F.; HORTA, M.C.; MORAESFILHO, J.; PACHECO, R.C.; LABRUNA, M.B.; AGUIAR, D.M. Seroprevalence and risk factors to Ehrlichia spp. and Rickettsia spp. in dogs from the Pantanal region of Mato Grosso State, Brazil. Ticks and Tick-Borne Diseases, v.2, n.4, p.213-218, 2011.

MELO, A.L.T.; COSTA, A.P.; MIYAZAKI, S.S.; STOCCO, M.B.; SEMEDO, T.B.F.; PACHECO, T.A.; WITTER, R.; PACHECO, R.C.; LABRUNA, M.B.; MARCILI, A.; AGUIAR, D.M. Rural area of the Brazilian Pantanal wetlands associated with the occurrence of anti-Leishmania spp. antibodies in dogs. Brazilian Journal of Veterinary Research and Animal Science, v.54, n.4, p.375-382, 2017.

MESQUITA, M.O.; TREVILATO, G.C.; SCHONS, M.S.; SARAIVA, L.H.; RODRIGUES, R.O.; CORBELLINI, L.G. Percepções ambientais e fatores associados à ocorrência de anticorpos anti-Leptospira sp. em cães de um reassentamento urbano no município de Porto Alegre, Estado do Rio Grande do Sul, Brasil. Revista Pan-Amazônica de Saúde, v.8, n.1, p.23-27, 2017.

MIOTTO, B.A.; GUILLOUXA, G.A.; TOZZI, B.F.; MORENO, L.Z.; HORA, A.S.; DIAS, R.A.; HEINEMANN, M.B.; MORENO, A.M.; FILHO, A.F.S.; LILENBAUM, W.; HAGIWARA, M.K. Prospective study of canine leptospirosis in shelter and stray dog populations: Identification of chronic carriers and different Leptospira species infecting dogs. PLoS One, v.13, n.7, p.1-23, 2018.

OIE (World Organization for Animal Health). Leptospirosis. In: Manual of Diagnostic Tests and Vaccines for Terrestrial Animals. Paris: World Organization for Animal Health, 2014, p.1-15.

PINTO, P.S.; LOUREIRO, A.P.; PENNA, B.; LILENBAUM, W. Usage of Leptospira spp. local strains as antigens increases the sensitivity of the serodiagnosis of bovine leptospirosis. Acta Tropica, v. 149, n.1, p.163-167, 2015.
RODRIGUES, A.M.A.; VASCONCELOS, S.A.; GONÇALES, A.P.; MORAES, Z.M.; SOUZA, G.O.; HAGIWARA, M.K. Anticorpos revelados pelo teste de inibição do crescimento de leptospiras in vitro (TICL) contra os sorovares Canicola, Icterohaemorrhagiae e Copenhageni em cães adultos revacinados anualmente com vacina comercial contendo bacterinas dos sorovares Canicola, Icterohaemorrhagiae, Grippotyphosa e Pomona. Pesquisa Veterinária Brasileira, v.33, n.5, p.627-634, 2013.

ROJAS, P.; MONAHAN, A.M.; SCHULLER, S.; MILLER, I.S.; MARKEY, B.K.; NALLY, J.E. Detection and quantification of leptospires in urine of dogs: a maintenance host for the zoonotic disease leptospirosis. European Journal of Clinical Microbiology \& Infectious Diseases, v.29, n.10, p.1305-1309, 2010.

SANTOS, S.A.; SERENO, J.R.B.; MAZZA, M.C.M.; MAZZA, C.A. Origin of the Pantaneiro horse in Brazil. Archivos de Zootecnia, v.41, n.154, p.371-381, 1992.

SANTOS, L.F.; GUIMARÃES, M.F.; SOUZA, G.O.; SILVA, I.W.G.; SANTOS, J.R.; AZEVEDO, S.S.; LABRUNA, M.B.; HEINEMANN, M.B.; HORTA, M.C. Seroepidemiological survey on Leptospira spp. infection in wild and domestic mammals in two distinct areas of the semi-arid region of northeastern Brazil. Tropical Animal Health and Production, v.49, n.8, p.1715-1722, 2017.

SILVA, F.J.; SANTOS, C.E.P.; SILVA, T.R.; SILVA, G.C.P.; LOFFLER, S.G.; BRIHUEGA, B.; ALARCON, M.F.F.; CURCI, V.C.M.; MATHIAS, L.A. Pesquisa de Leptospiras e de anticorpos contra Leptospiras em animais e humanos de propriedades rurais nos biomas brasileiros Pantanal e Caatinga. Brazilian Journal of Veterinary Research and Animal Science, v. 52, n.3, p.234-248, 2015.

SILVA, E.R.D.F.S.; CASTRO, V.; MINEIRO, A.L.B.B., PRIANTI, M.G.; MARTINS, G.H.C.; SANTANA, M.V.; BRITO, L.M.; SILVA, S.M.S. Análise sócio demográfica e ambiental para ocorrência de anticorpos anti-Leptospira em cães de Teresina, Piauí, Brasil. Ciência \& Saúde Coletiva, v.23, n.5, p.1403-1414, 2018.

VIEIRA, A.S.; ROSINHA, G.M.S.; VASCONCELLOS, S.A.; MOARIS, Z.M.; VIANA, R.C.; OLIVEIRA, C.E.; SOARES, C.O.; ARAÚJO, F.R.; MOURÃO, G.M.; BIANCHI, R.C.; OLIFIERS, N.; RADEMAKER, V.; ROCHA, F.L.; PELLEGRIN, A.O. Identificação de mamíferos silvestres do Pantanal Sul-mato-grossense portadores de Leptospira spp. Ciência Animal Brasileira, v.14, n.3, p.373-380, 2013. 